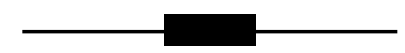

\title{
Introduction
}

\section{A New Journal for Contemporary Environmental Challenges}

Social scientists have been writing about the relationships between people and their surroundings for as long as there has been social scientific inquiry. Fields such as anthropology, economics, history, human geography, law, political science, psychology, and sociology all have long and rich histories of contributing to and pioneering socio-environmental analysis. However, the past 20 years have seen a proliferation of scholarship in the social sciences that is focused on environmental issues. This is due, in part, to changes in our environment that have profound implications for the future of both human society and the environment. It is also due, in part, to the ways in which environmental practitioners have portrayed the causes of these changes. In the 1970s, social scientists, concerned with the ways in which the causes of environmental changes were being attributed to some peoples and not others, felt that their knowledge of social processes and social systems could shed light on these issues (see Blaikie and Brookfield 1987). They thought that the methods and theories of the social sciences could and should be brought to bear on questions about contemporary environmental changes. Climate change, the water crisis, deforestation, desertification, biodiversity loss, the energy crisis, nascent resource wars, environmental refugees, and environmental justice are just some of the many compelling challenges facing society today that were identified by these early scholars as sites in need of social scientific analysis.

Most social scientists approach environmental issues by asking why a phenomenon is taking place and then trace the answers out across time and space (cf. Vayda 1983). More often than not, they also contextualize the answers they find within larger conversations, debates, and theories in and across disciplines and thus attend to cultural, historical, political, and economic contexts. In asking questions and then contextualizing the answers within social scientific theory and discourse, they sometimes write in ways that are difficult for outsiders to decipher. This is also the case in the natural sciences. Within atmospheric science, biology, chemistry, ecology, geology, geophysics, hydrology, oceanography, physical geography, physics, and soil science, scholars have developed their own vernaculars and systems of contextualization. These competing vernaculars often make it seem as if social and natural scientists cannot (and do not) communicate at all.

Environment and Society: Advances in Research is meant to address these key issues, among others. This new journal focuses on contemporary environmental topics that large numbers of social scientists in multiple disciplines write about. We provide peer-reviewed articles that analyze and summarize existing research and that offer suggestions for new directions in research. These articles are not steeped in disciplinary vernaculars, but they do incorporate contemporary theory. With this, they afford a window into social science without editing out the insights brought to the empirical world through rigorous engagements with theory. The journal also offers reviews of books concerned with environmental issues that are of significance for both the social and 
natural sciences. The editors see the journal as a site for dialogue across disciplines within the social sciences and as a resource to which natural scientists, policy makers, environmental practitioners, and activists can turn in order to understand better the work that social scientists do.

This first volume of Environment and Society: Advances in Research focuses on social scientific analyses of climate-related topics. The first article, by Noel Castree, is titled "Neoliberalism and the Biophysical Environment: A Synthesis and Evaluation of the Research." Many social scientists working on the environment in general and climate-related issues in particular frame their work in terms of the socio-economic philosophy that has come to be known as 'neoliberalism. Castree explains this philosophy and shows how the policy ideas and practices that emerge from it affect both environments and societies. He then reviews the ways in which social scientists have attended to neoliberalism and environmental issues for the past decade. Castree's article is about neoliberalism, but it can also be read as an example of the ways in which social scientists work to understand the confluence of the various processes mentioned above and then build social theory from these understandings. 'Neoliberalism', 'neoliberalization', and 'econeoliberalism' are terms in the social scientific vernacular. In reviewing a substantial literature, Castro unpacks these concepts in a clear and compelling way, opening them up to wider transdisciplinary understanding.

In “Neoliberal Water Management: Trends, Limitations, Reformulations," Kathryn Furlong frames her analysis of water policy and management in terms of neoliberalization. Furlong describes the claims of neoliberal reformers and of their opponents in Bolivia, her long-term site of research, situating them in a much broader discussion of the environmental aspects of the philosophical tenets that drive neoliberal reforms. She shows how that philosophy is mobilized, not only when it comes to addressing water shortage issues, but also when other matters, such as climate, are dealt with.

In his article, "Controversies in Climate Change Economics," Robert Eastwood explains how economists understand and evaluate the most pressing climate-related issues. He demonstrates how the economic and scientific uncertainty associated with climate creates a policy context that requires innovative measures in assessment and policy crafting. Eastwood also examines other economic reviews of climate change and climate change policy, illustrating how different approaches to climate policy analysis exist within economics. Part of what is compelling about Eastwood's article is the way in which he clearly documents the issues that are important to economists and how those issues then drive the analytic tools that they bring to the entire climate debate.

Richard Ladle and Paul Jepson's article, “Origins, Uses, and Transformation of Extinction Rhetoric," examines the role of extinction in climate-related discussion and illustrates how social scientists contextualize the questions they ask in wider frames. The authors trace the history of academic and political discussions about extinction in order to show how these discourses influence policy and practice. They carefully review studies concerned with extinction from multiple disciplines, and through this they provide suggestions as to how conservation practitioners and policy crafters might draw on this wide literature in order to create more robust approaches to issue of extinction.

The next two articles, "Climate Changing Small Islands: Considering Social Science and the Production of Island Vulnerability and Opportunity," by Amelia Moore, and "AdaptationGenuine and Spurious: Demystifying Adaptation Processes in Relation to Climate Change," by Thomas Thornton and Nadia Manasfi, provide literature analyses that work to contextualize case studies. In doing so, they demonstrate how contextualization makes the social scientific analysis of empirical evidence richer. In her review of research literature, Moore examines the processes by which small islands have been incorporated into climate-related debates. She then 
contextualizes state-specific discussions about climate change science and policy, vulnerability indexing, and sustainable economic growth in the Bahamas within this literature. Thornton and Manasfi review the social scientific literature on adaptation. After carefully assessing whether adaptation to climate change can be planned and managed, they show how contemporary governance frameworks fail to address the growing pressure that climate stress is exacting on indigenous peoples in the far north of Alaska and Canada and in the Arctic Circle. Both of these articles show the current and potential human aspects of the climatic-related economics discussed by other authors.

In their article "Climate Change Resilience and Adaptation: Perspectives from a Century of Water Resources Development," Clive Agnew and Philip Woodhouse argue that much of the debate about how societies adapt to climate change is in fact a discussion about water management. They offer a careful analysis of the literature on resilience and adaptation while exploring the reasons for failure and success in adapting to water scarcity and degradation in different circumstances. Their research is particularly pertinent for dialogues about coping with climate change.

Finally, in the book reviews section, we provide critiques of 12 environmentally focused social scientific books published between 2007 and 2010. Through this feature of the journal, we hope to show how publications in the social sciences speak to issues of broad concern across disciplines. The reviews in this volume examine environmental conservation practice, science and policy, long-term global environmental changes, the medical effects of pollution, the economic aspects of disasters, urban ecology movements, the relationship between ecological and social change, environmental history, and the environmental politics of economic development.

Paige West, Dan Brockington, Jamon Halvaksz, and Michael Cepek

\section{REFERENCES}

Blaikie, Piers M., and H. C. Brookfield. 1987. Land Degradation and Society. London: Methuen. Vayda, Andrew P. 1983. "Progressive Contextualization: Methods for Research in Human Ecology."

Human Ecology 11 (3): 265-281. 